\title{
Characterization of Transplant Generations of Primary Rat Adenocarcinomas
}

\author{
TORU SUGIYAMA, TAKASHI NISHIDA, KIMIO USHIJIMA, \\ HIDEKI KATABUCHI, KENICHI SHIBUE, MASAMICHI NAKANAMI, \\ MICHIAKI YAKUSHIJI AND TOSHI KATO
Department of Obstetrics and Gynecology, Kurume University School of Medicine, Kurume, 830 Japan

Received for publication May 26, 1986

\begin{abstract}
Summary: DMBA-induced adenocarcinomas were transplanted into the neonatal or young rats of the same strain (Wistar). Following subcutaneous injection, tumors exhibited two phases of growth: an inititial avascular phase characterized by slow growth, followed by a later phase of rapid growth in which the tumor became vascularized. The: transplanted tumor was more hypervascular than the primary tumor. Histologically, the primary autochthonous tumors and the transplanted counterparts were similar. The most striking result of transplantation was a much more homogeneous solid pattern than occurred in the primary tumor. The second histologic finding was a reduced stromal reaction. Moreover, in the central area of the tumor, the relationship between the vasculature and cell proliferation was observed. The transplanted tumors may provide a useful experimental model for laboratory studies on the chemotherapy of ovarian cancer.
\end{abstract}

Key words: ovarian cancer - experimental induction - 7,12-dimethylbenz [a] anthracene - transplantation - histologic change

\section{Introduction}

Selective induction of ovarian cancer in rats by the administration of 7,12 dimethylbenz [a] anthracene (DMBA) was first reported by our experimental group (Kato et al. 1974). The incidence of tumorigenesis was approximately $48 \%$ (Katabuchi, 1983; Sugiyama, 1981). The tumorigenic lesion was an adenocarcinoma with both glandular and solid structures. The DNBAinduced adenocarcinoma has been successfully transplanted into the same strain rats in nearly all attempts, where they have grown to large sizes and have subsequently been serially passed from rat to rat with ease. Metastases to regional lymph nodes were rarely seen.

The present study was proposed to compare the morphology of the original tumor and its transplanted counterparts in neonatal or young rats of the same strain.

\section{Materials and Methods}

The rat autochthonous adenocarcinoma induced by DMBA was serially transplanted from rat to rat by subcutaneous inplantation of tumor fragments $\left(4.0 \mathrm{~mm}^{3}\right)$. The three major diameters of the tumor were measured every other day and the products of these three dimensions were recorded as the volume of the tumor according to the formula; (lenghth) $\times$ (width) $\times$ (thick ness) $\times 0.5$. At the $7 \mathrm{th}, 14 \mathrm{th}, 21 \mathrm{st}, 28 \mathrm{th}$ and 35 th post-transplantation day, some of the rats in the 16 th transplant genera- 
tion were anesthetized with ether and perfused through the descending arota, first with a physiological saline and then with Bouin's solution or microfil (Canton Biomedical product Co.). Six to eight weeks after transplantation, regional lymph nodes with suspected metastases were removed. Histologic sections were immediately fixed in Bouin's solution and stained with hematoxylin and eosin, PAS and HOPA. Microangiography was performed under a dissecting microscope.

\section{Results}

Twenty tumor-bearing rats in the 16 th generation were selected at random and used for this study.

1) The transplanted tumors exhibited 2 phases of growth (Fig. 1). During the first seven days, all the tumors had a volume of approximately $4.0 \mathrm{~mm}^{3}$ which was near their transplantation size. Thereafter they began to grow gradually for about seven days and then grew rapidly. The tumors appeared spheroidal or ellipsoidal within one week after transplantation. When the tumors reached approximately $500 \mathrm{~mm}^{3}$ in volume the central portion of the tumors became obviously necrotic, leaving a peripheral shell of living cells. All the tumors appeared well circumscribed by a capsule of connective tissue with obvious vascular development (Fig. $2 \cdot \mathrm{a}, \mathrm{b})$.

2) Microscopically, the characteristics of the transplanted tumor were similar to those of the primary adenocarcinoma. However, they had a much more homogeneous solid pattern than the primary tumors. They appeared less differentiated than the primary tumors and histologically they would be classified as undifferentiated adenocarcinomas. In addition, the characteristics of the tumors were relatively stable over a number of transplant generations in most instances and no al-

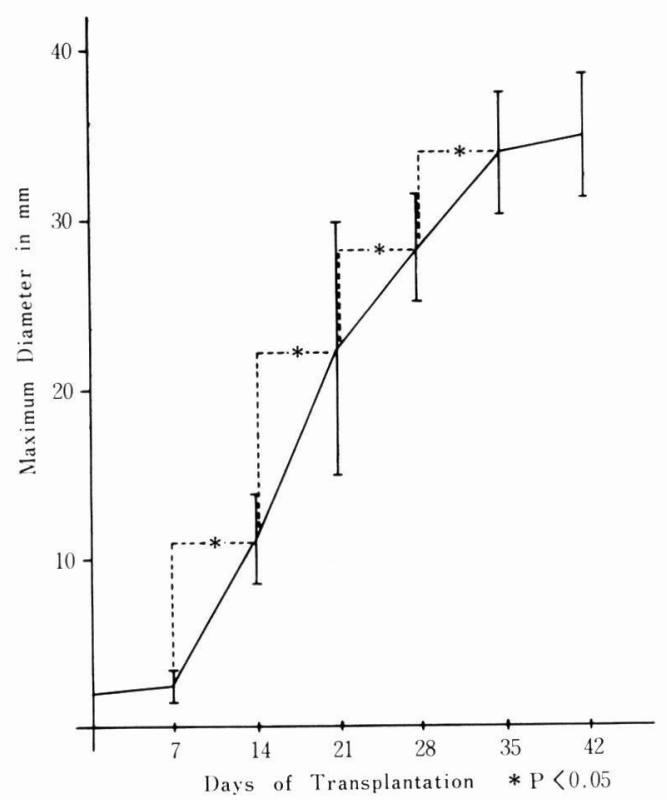

Fig. 1. Growth curve of transplanted tunors.

teration of the histologic picture was observed. Neoplastic cells were arranged in sheets, cords or small compact masses supported by a scant, delicate connective tissue stroma with obvious vascular development. Moreover, a reduced stromal reaction was observed. Dense stromal and inflammatory reactions were sometimes seen in the primary tumor, but in the corresponding transplants, the stroma had a fine reticular appearance, with few in flammatory cells. The neoplastic cells were round or oval, becoming elongated in certain areas with large nuclei, prominent nucleoli, and adundant cytoplasm. Scattered atypical mitotic figures were present (Fig. 3-a, b). The central area of the tumor was interspersed with islands of viable neoplastic cells which survived around capillaries. The islands were surrounded by necrosis and connective tissue, where many histiocytes were observed. The surviving cells were irregularly shaped with a scant cytoplasm. Most nuclei had a coarse chromatin pattern. Nucleoli were 
seen The mitotic rates were low (Fig. $4-\mathrm{a}, \mathrm{b})$.

3) In the capsule of the transplanted tumor, many dilated vessels, induced from subcutaneous vessls of the host, were observed (Fig. 2-b). New capillaries were elicited from the host, and had penetrated the tumor within seven days (Fig. 5-a, b). After fourteen days, the transplanted tumor had a dense vascular network (Fig. $6-a, b)$. Viable tumor cells and fine connective tissue with many small blood vessels were seen throughout the tumor (Fig. $3,6-b)$.

4) Concerning the lymphatic involvement of the transplanted tumor, a glandular structure had reappeared and the histologic picture was strikingly similar or identical to that of the primary tumor (Fig. 7).

\section{Discussion}

The purpose of this study was to characterize the morphology of transplanted tumors in a single strain of rats. The results of this study have added to our understanding of the nature of the autochthonous tumor resulting from chemical carcinogenesis and the progression to a transplanted tumor. It is clear that the transplanted tumor, after repeated transplantations, bears a resemblance to the primary tumor but some tumors vary in crucial characteristics.

Histlogic examination revealed much less adenocarcinoma differentiation than in the primary tumor. Generally, they were poorly differentiated neoplasms characterized by high mitotic activity. Definitive evidence of a solid pattern was noted, although glandular structures were scarcely seen. Previous investigators have suggested that a single neoplasm can contain a number of phenotypically distinct tumorigenic cell types (Daniel et al. 1978; Margaret et al. 1978). Previous work in our laboratory seemed to support this heterogeneity. The DMBA-induced adenocarcinoma had mixed populations of estrogen receptor positive and negative cells. Furthermore, administration of estrogens altered the growth rate and the phenotypically histologic pattern of DMBA-induced adenocarcinomas (Katabuchi, 1983). However at present, the reason that DMBA-induced adenocarcinomas are multicellular in origin cannot be explained because the histologic pattern of the lymphatic involvement revealed a concomitant type of adenocarcinoma. The reappearance of glandular structures in the lymphatic involvement derived from rats with subcutaneous transplants indicated that the degree of differentiation and/or phenotypic pattern of the neoplastic cells, including stem cells, could be altered by the tumor and host environment (Buick and Pollak, 1984). The second important histologic characteristic of the transplant was the reduced stromal reaction. In the transplanted tumor the stroma had a fine reticular appearance, with few inflammatory cells (Lamerton and Steel, 1975). Stromal tissue induced by a tumor may play an important role in the propagation and possibly in the response to chemotherapy.

In the central area of the tumor, the relationship between the vasculature and the characteristics of cell proliferation were observed. Neoplastic cells adjacent to blood vessels seemed to be the surviving cells that were selected from the various neoplastic cells of the original tumor. These islands depend on a vascular system for the supply of oxygen and nutrients. Previous reports suggested that solid tumor growth was not continuous, but might be separated into two stages, avascular and vascular (Knighton et al. 1977). It is possible that the islands are the units of neoplastic cells which develop into frank tumors at the beginning of vascular phase. In addition, microangiography showed that the transplanted tumor was more hyper- 
vascular than the primary tumor (Oda, 1983).

The morphological observations lead to the conclusion that the value of this experimental system lies in its usefulness for testing antitumor agents. The relationship between the tumor morphology of primary tumors and transplants in the autochthonous hosts is now under investigation, using DMBA-induced rat adenocarcinomas.

\section{References}

Buick, R.N. and Pollak, M.N. (1984). Perspectives on clonogenic tumor cells, stem cells, and oncogenes. Cancer Res. 44, 4909-4918.

Daniel, L.D., Henryk, M.K., Beverly, A.B., ZuZANa, F., Renee, V. and Gloria, H.H. (1978). Heterogeneity of tumor cells from a single mouse mammary tumor. Cancer Res. 38, 3164-3181.

Katabuchi, H. (1983). A hormonal impact on DMBA-induced rat ovarian cancer. (Detection of hormone-receptor and resultant morphologic changes after estrogen application.) Acta Obst. Gynac. Jpn. 34, 1634-1640.

Kato, T., Yakushiji, M., Tsunawaki, A. and IDE,
K. (1974). Studies of experimental ovarian tumors. (Ovarian tumors developed in rats receiving chemical carcinogen 9,10-dimethyl1,2-benzanthracene.). Kurume Med. J. 21, 11-19.

Knighton, D., Ausprunk, D., TApper, D. and FORKMAN, J. (1977). Avascular and vascular phases of tumor growth in the chick embryo. Br. J. Cancer, 35, 347-356.

Lamerton, L.F. and Steel, G.G. (1975). Growth kinetics of human large bowel cancer growing in immune-deprived mice and some chemotherapeutic observations. Cancer, 36, 24312436.

Margaret, L.K., Eilene, G. and Isaiah, J.F. (1978). Metastatic heterogeneity of cells from an ultraviolet light-induced murine fibrosarcoma of recent origin. Cancer Res. 38, 29622967.

OdA, T. (1983). Evaluation of cancer chemotherapy using rat ovarian cancer induced by DMBA. (Observation of histologic effects by light and transmission electron microscopy, and changes in vascular system after CisDDP treatment.). Acta Obst. Gynaec. Jpn. 35, 315-320.

Sugryama, T. (1981). Cancer chemotherapy model using autochthonous ovarian cancer in rats. (Effect of ifosfamide on DMBA induced tumor.). Kurume Med. J. 44, 731-747. 

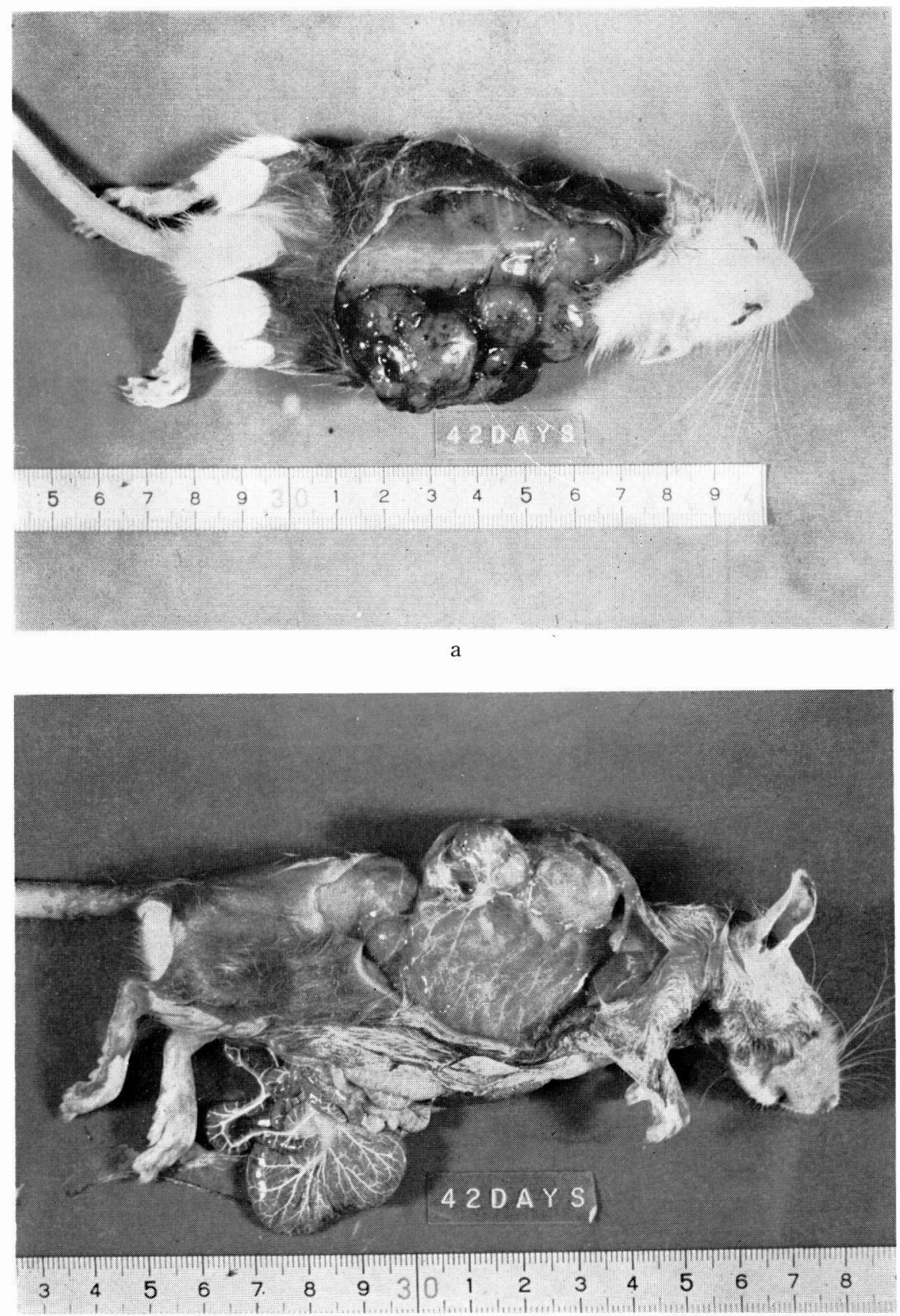

b

Fig. 2. Subcutaneous transplantation of a DMBA-induced tumor in a rat. a) The tumor was surrounded by a capsule of connective tissue with obvious vascular development.

b) A microfil was injected into the rat via the descending aorta. Small blood vessels continuous with those of the host surrounded and penetrated the transplant. 


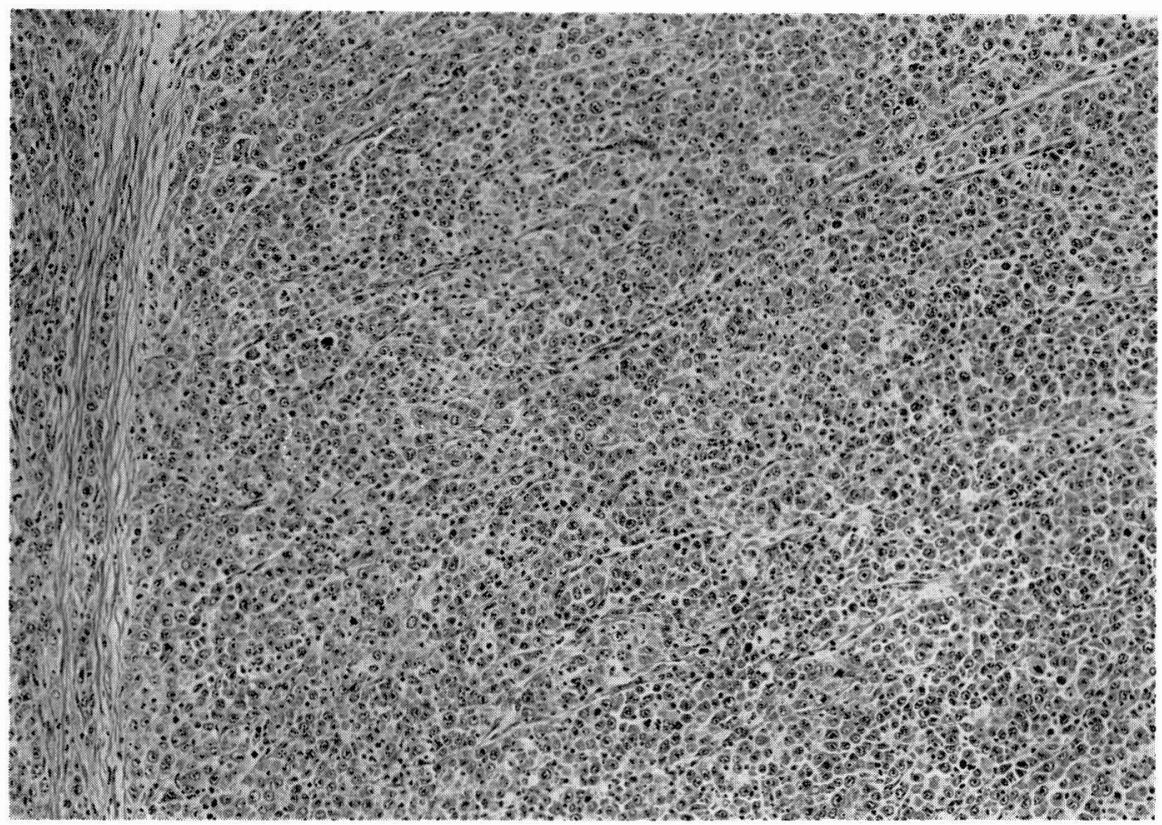

a

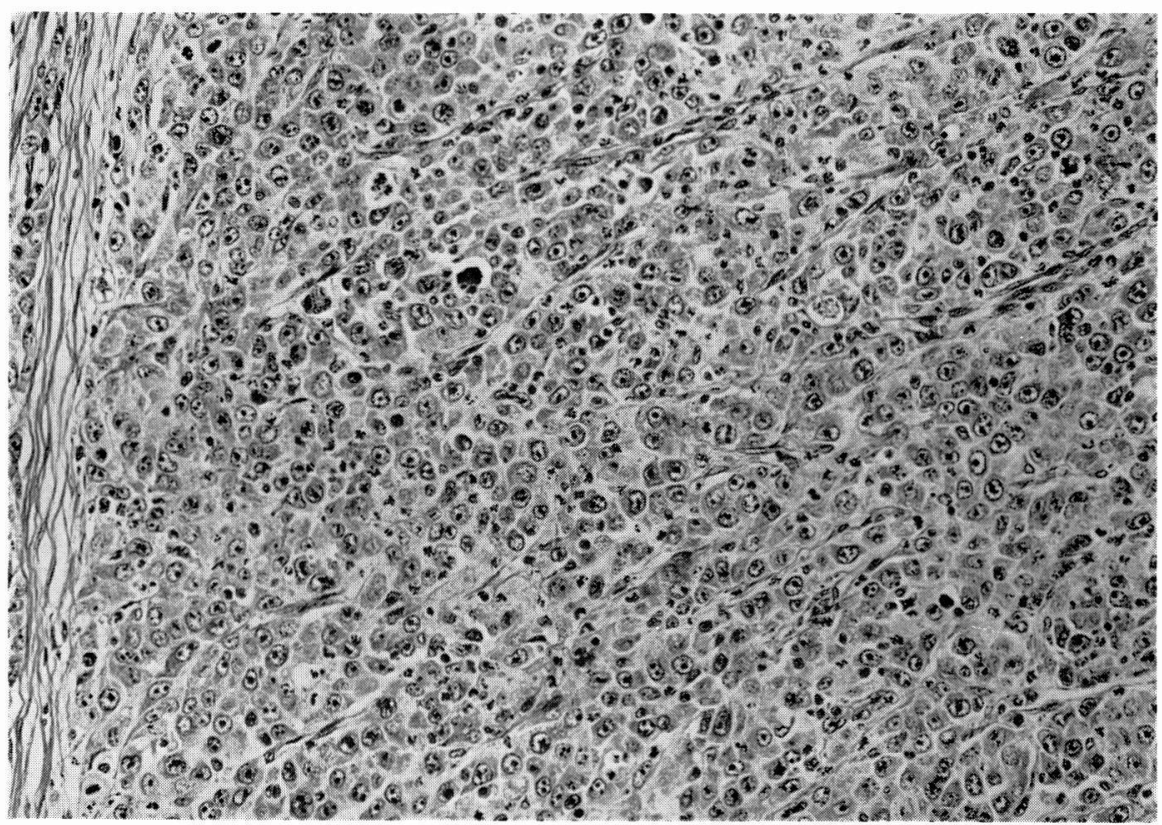

$\mathrm{b}$

Fig. 3 .

a) Histologic examination of the solid structure showed an undifferentiated adenocarcinoma with many mitotic figures. The tumor, supported by a scant, delicate fibrovascular stroma, has a reduced stromal reaction. $\mathrm{H}$ and $\mathrm{E} \times 100$.

b) Higher magnification of the same tumor. $\mathrm{H}$ and $\mathrm{E} \times 200$. 


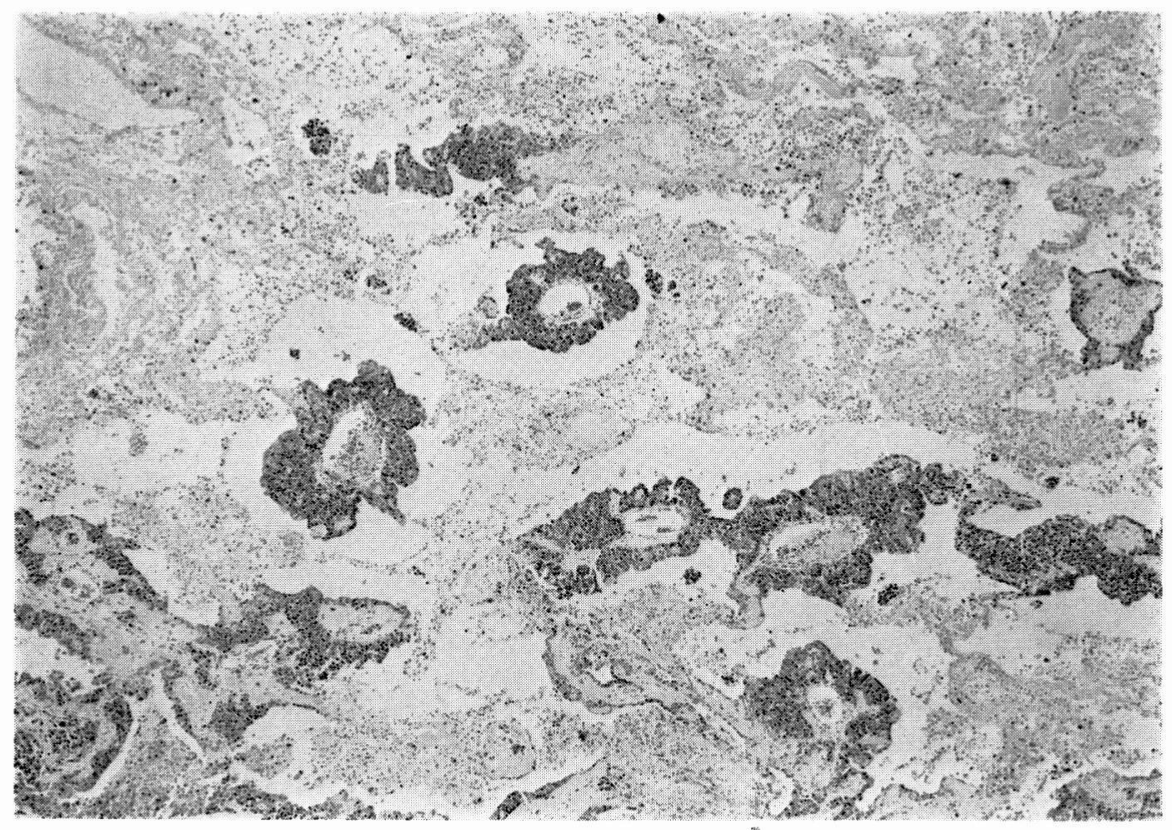

a

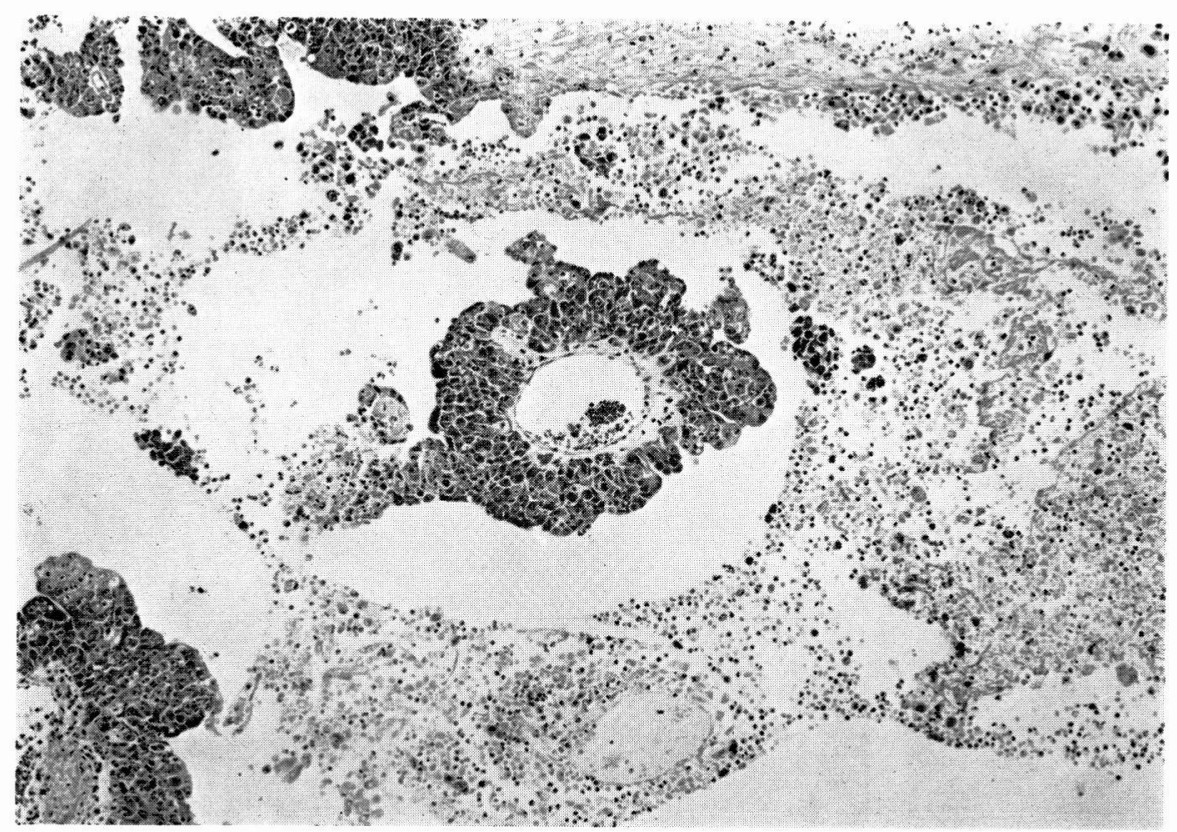

$\mathrm{b}$

Fig. 4.

a) Islands of degenerated neoplastic cells. $\mathrm{H}$ and $\mathrm{E} \times 50$.

b) The cells surviving around capillaries had irregular shapes and scant cy toplasm. Many histiocytes were observed. $\mathrm{H}$ and $\mathrm{E} \times 200$. 

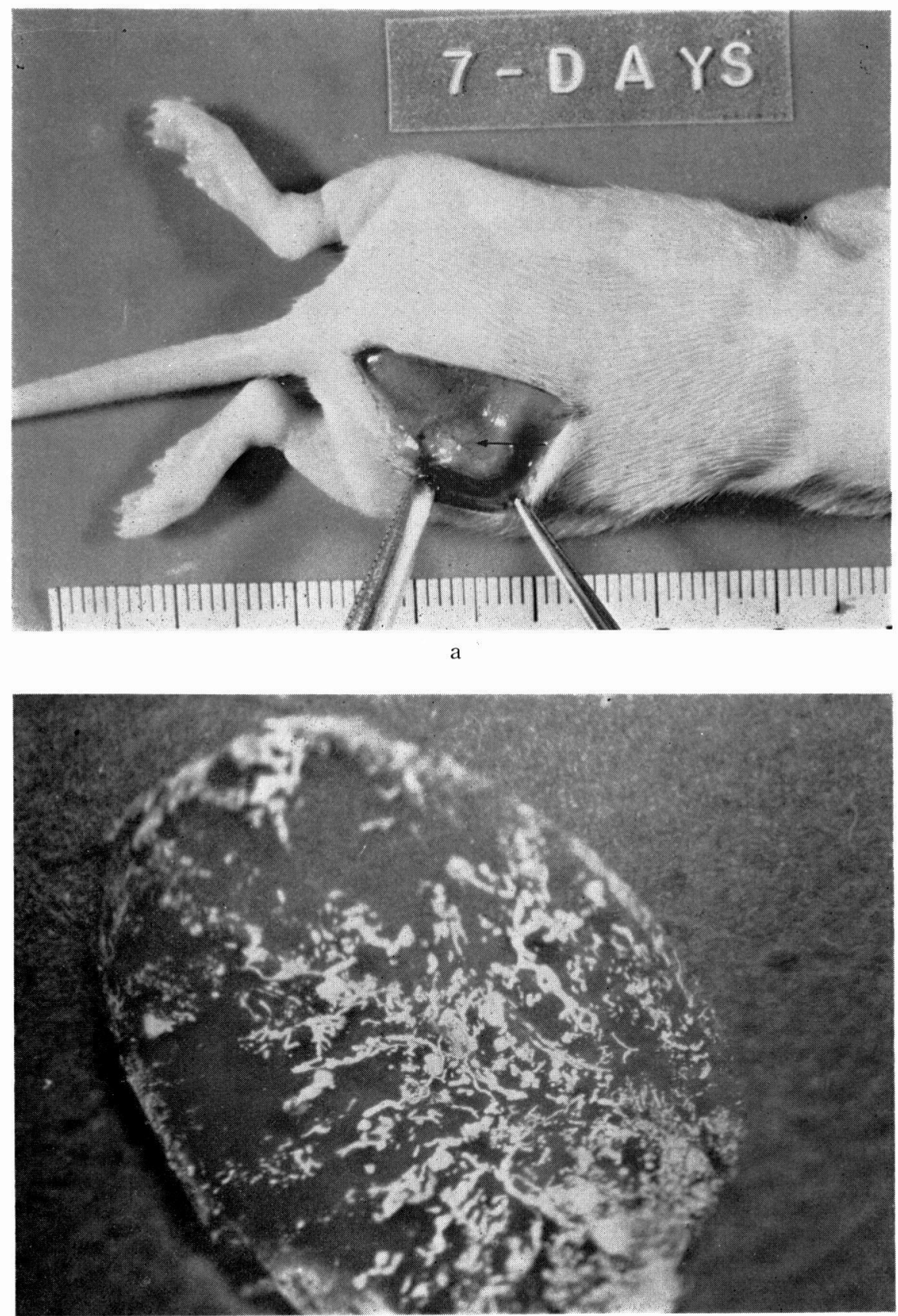

b

Fig. 5. Transplant, after 7 days.

a) The tumor appeared spheroidal and adhered to the host tissue. The arrow indicates thick-walled vessels coursing to, over, and into the $5 \mathrm{~mm}$ transplant.

b) Microangiography of a tumor 7 days after transplantation. Neoplastic vessels at the periphery of the transplants have penetrated and formed a rough vascular network. 


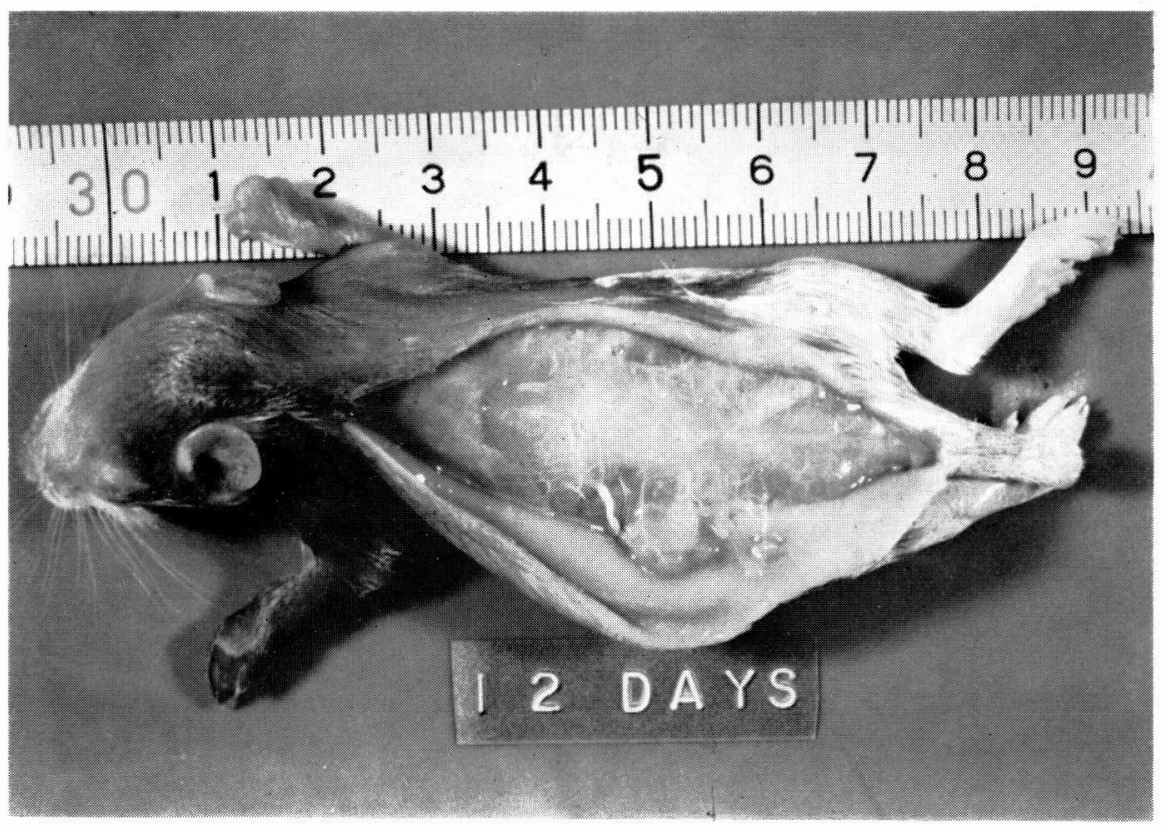

a

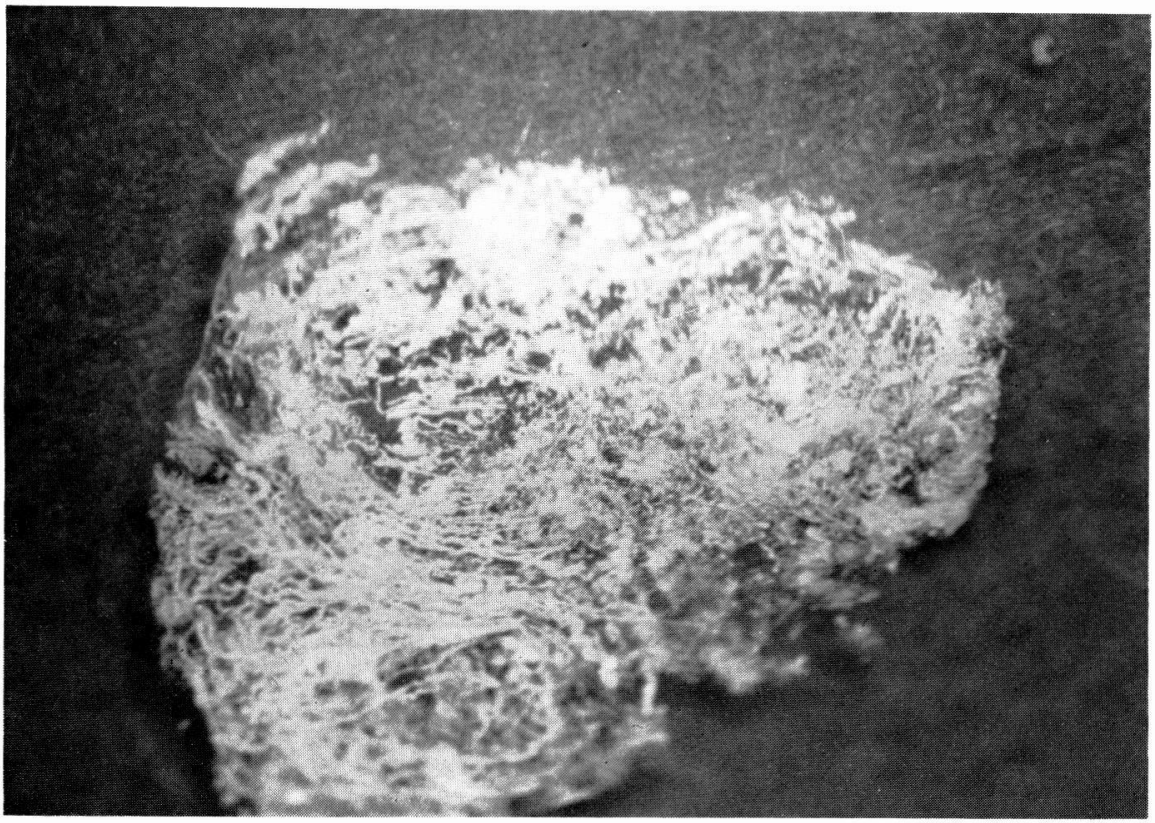

b

Fig. 6. Transplant, after 12 days.

a) A microfil was injected via the descending aorta. Many dilateted vessels were elicited in the host, and penetrated the tumor.

b) Microangiography: Rich microvascular networks became more abundant. 


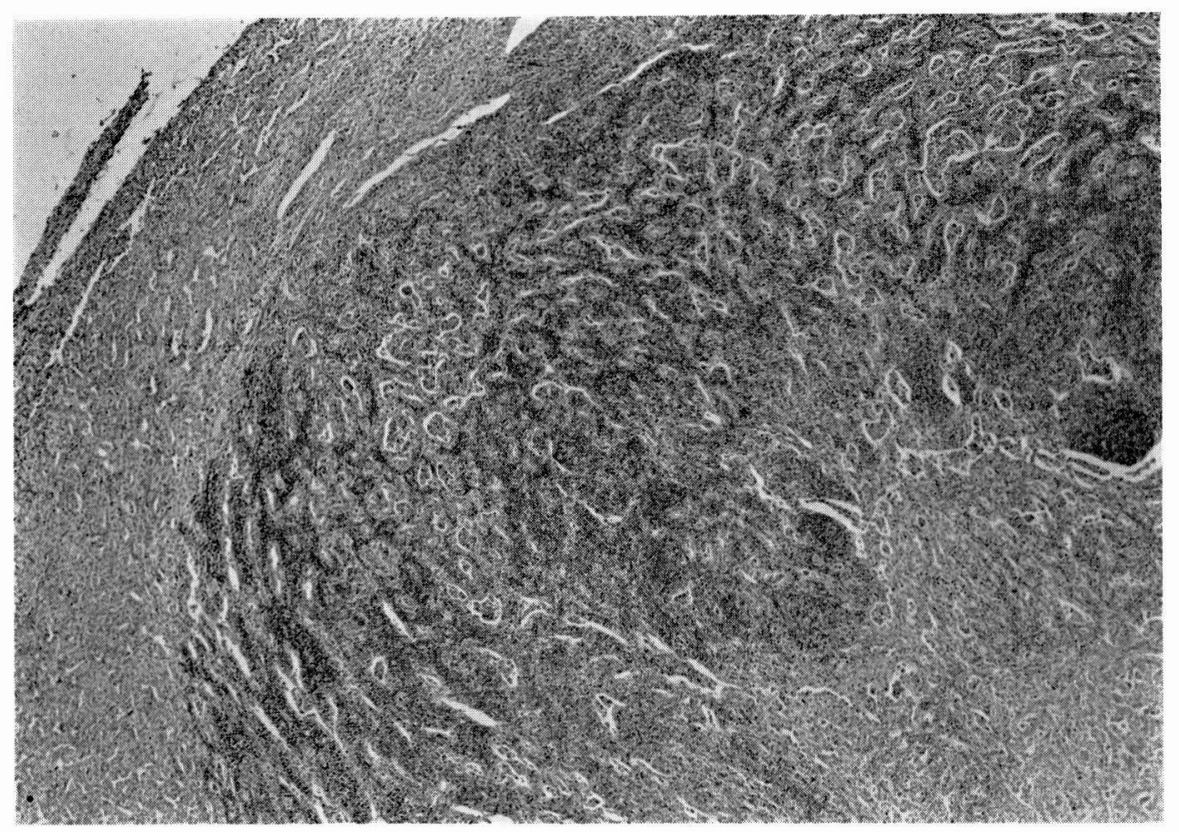

Fig. 7. Metastasis to the axillary lymph nodes 49 days after transplantation. Neoplastic cells were predominantly grouped in glandular structures. $\mathrm{H}$ and $\mathrm{E} \times 100$. 